\title{
In situ measurement of survival and growth of Lophelia pertusa in the northern Gulf of Mexico
}

\author{
Sandra Brooke $e^{1,2, *}$, Craig M. Young ${ }^{1}$ \\ ${ }^{1}$ Marine Conservation Biology Institute, 2122 112th Avenue NE, Bellevue, Washington 98004, USA \\ ${ }^{2}$ Oregon Institute of Marine Biology, PO Box 5389, Charleston, Oregon 97420, USA
}

\begin{abstract}
Growth rates of Lophelia pertusa were directly measured using stained coral fragments, deployed in situ for more than $1 \mathrm{yr}$ on small transplant units. Survival of the fragments was quantified after deployment (1) within dense coral areas (high coral) and (2) on exposed bare substrate (no coral) in the same area as the reef. Samples of $L$. pertusa were collected from Viosca Knoll (430 to $520 \mathrm{~m}$ depth), northern Gulf of Mexico in July 2004, stained with Alizarin red, photographed and secured onto transplant units for redeployment. The transplants were recovered in September 2005 and percent polyp survival, growth (mm of linear extension) and number of new polyps were recorded. Survival was high $(>90 \%)$ for all transplant units and the average linear growth rate observed $(\sim 3.77$ and $2.44 \mathrm{~mm} \mathrm{yr}^{-1}$ for high coral and no coral sites, respectively) fell at the lower end of the published range for this species. There was no significant difference between any of the survival or growth parameters between sites. The stain bands on the coral sections illustrated double growth centers, which introduces an additional level of complexity when assessing growth through lateral banding patterns. Growth rates of $L$. pertusa have been inferred using various direct and indirect methods; however, this study represents the first direct measurement of in situ growth for this species.
\end{abstract}

KEY WORDS: Lophelia pertusa $\cdot$ Growth rates · Survival · Gulf of Mexico $\cdot$ Deep-water coral $\cdot$ In situ

\section{INTRODUCTION}

The deep-water scleractinian Lophelia pertusa (L. 1758; Caryophyllidae) is the most extensively studied of all deep coral species and has been recorded from most oceans, with the exception of the polar regions (Zibrowius 1980, Cairns 1994, Rogers 1999, Freiwald et al. 2004, Roberts et al. 2009). The documented depth range for this species varies widely from 39 to $2775 \mathrm{~m}$, but it is most commonly found on topographic features and the edges of continental shelves at 200 to $400 \mathrm{~m}$ (Wilson 1979a, Mortensen et al. 1995, Lumsden et al. 2007, Roberts et al. 2009), and at temperatures between 4 and $8^{\circ} \mathrm{C}$. The fjords of Sweden and Norway support the shallowest known L. pertusa colonies, where offshore ocean water is funneled into the narrow waterways and provides essentially deep ocean conditions at shallow depths (Stromgren 1971), but the largest reefs are found in the north Atlantic off Norway (Hovland et al. 1994, 1997), the Faroe Islands (Frederiksen et al. 1992) and off the southeastern coast of the USA (Ross \& Nizinski 2007). L. pertusa is a colonial species that forms dendroid branching colonies, which frequently anastomose (fuse together) creating complex and stable structures. Colonies typically develop from an initial larval settlement into small irregular bushes and then into large, roughly hemispherical colonies, which eventually coalesce into 'thickets' (Squires, 1964) or 'rings' (Wilson 1979b). These structures are composed of an inner core of dead coral with a live outer layer. The dead coral provides substrate for settlement of a diverse and abundant assemblage of benthic fauna and, as growth continues, the thickets aggregate into the coppice stage (Squires 1964). Over time, the corals form large biogenic structures that may be $>500 \mathrm{~m}$ high and regionally extensive (Hovland et al. 1997, Paull et al. 2000, Roberts et al. 2009). For an overview of carbonate mound formation, see Roberts et al. (2009). 
The first attempt at estimating growth rates of Lophelia pertusa was in the late 19th century from colonies that had settled on trans-Atlantic telegraph cables (Duncan 1877). Since then, various methods have been used to assess growth of not only L. pertusa, which will be covered in greater detail later, but other deep-water scleractinians such as Desmophyllum cristigalli (Cheng et al. 2000, Risk et al. 2002, Adkins et al. 2004), Enallopsammia rostrata (Adkins et al. 2004), Madrepora oculata (Orejas et al. 2008), members of the genera Corallium (Grigg 2002, Andrews et al. 2005), Keratoisis (Thresher et al. 2007, Noé et al. 2008) and Primnoa (Risk et al. 2002, Mortensen \& BuhlMortensen 2005), antipatharians (Grigg 1976, Roark et al. 2006, Love et al. 2007) and the precious gold coral Gerardia spp. (Grigg 1976, Roark et al. 2006). Age and growth of deep-water corals can be measured in terms of radial or linear extension. The tree-like colonies of large gorgonians, black corals and precious corals have a single basal region that expands and lays down growth rings throughout the life of the colony; therefore, radial rings and changes in skeletal isotopic signature are most commonly used to estimate age and growth in these corals. However, for the structureforming scleractinia, which do not have this tree-like structure, measuring linear extension of the branches or increase in colony size are more typical approaches (see Roberts et al. 2009).

Growth rates of Lophelia pertusa have been inferred from measurements of colonies growing on man-made structures such as telegraph cables and oil platforms (Duncan 1877, Wilson 1979a, Bell \& Smith 1999, Gass \& Roberts 2006). These estimates range widely from 6 to $35 \mathrm{~mm} \mathrm{yr}^{-1}$ and although natural variability may account for some of this range, the growth calculations assume that the largest colonies are as old as the structure itself, which is probably not the case. This method will therefore generally overestimate age and thus underestimate growth rates. Another factor to take into account with this method is that hemispherical colonies expand simultaneously in all directions, so the radius rather than the diameter should be used as the numerator for growth estimates. Linear and radial growth rates of $L$. pertusa have been estimated using skeletal stable isotopes of carbon $\left(\delta^{13} \mathrm{C}\right)$ and oxygen $\left(\delta^{18} \mathrm{O}\right)$ (Mikkelsen et al. 1982, Freiwald et al. 1997, Mortensen \& Rapp 1998, Rogers 1999), and have also resulted in a wide range of growth rates: 6 to $25 \mathrm{~mm}$ $\mathrm{yr}^{-1}$. This method relies on interpretation of the skeletal isotopes in relation to growth bands, which is prone to errors and assumptions. The isotope analysis can also be influenced by sample location within the polyp and can lead to misinterpretation (Mortensen \& Rapp 1998). Direct measurements of coral growth measured in aquaria for L. pertusa (Mortensen 2000, Orejas et al.
2008) reported linear extension rates of 9.4 and 15 to $17 \mathrm{~mm} \mathrm{yr}^{-1}$, respectively, but as with the other methods, there are obvious artifacts involved with extrapolating aquaria observations to field growth rates. The present study was the first to directly measure growth of L. pertusa in the field using a visual method that allowed us to observe variation and extent of growth in this species without the experimental artifacts of the methods described previously.

Although all of these methods have varying degrees of potential error associated with them, the great plasticity of colony morphology observed in the field (Cairns 1979, Brooke \& Schroeder 2007, Roberts et al. 2009) suggests that growth of Lophelia pertusa is naturally highly variable. Although little is known of the proximal causes of the great variation in growth rates and morphology seen in L. pertusa, the abundance, distribution and growth of deep-water corals may be influenced strongly by a variety of biotic and abiotic factors such as food supply, turbidity, temperature, hydrography and ocean chemistry (Cairns \& Parker 1992, Guinotte et al. 2006, Thiem et al. 2006, White et al. 2007, Roberts et al. 2009). Mortensen (2000) suggested that growth line formation in L. pertusa is correlated with seasonal temperature variations but also noted that temperature may covary with other factors such as food supply. Aquarium studies of L. pertusa in Norway and Scotland (Mortensen 2001, Roberts \& Anderson 2002) indicated that increased food supply was followed by high extension rates; therefore, seasonal changes in food supply, rather than temperature directly, may control growth rates of $L$. pertusa in the field.

The deep Gulf of Mexico is dominated by fine sediments, but large areas of hard substrata occur in the form of authigenic carbonate, which is produced as a byproduct of coupled methane oxidation and sulfate reduction by microbial communities (Aharon \& Fu 2000, Boetius et al. 2000). In some places, these hard substrata are colonized by various types of sessile benthic organisms, including Lophelia pertusa, and in other nearby areas there are expanses of uncolonized but apparently suitable substratum (Brooke \& Schroeder 2007, authors' pers. obs.). The lack of community development may be caused by (1) limited larval delivery, (2) heavy post-settlement mortality, or (3) localized environmental factors that prevent the habitat from supporting colony development. This is speculative since there are no local data for these particular areas, but factors affecting this lack of development may include hydrography patterns that do not deliver coral larvae or sufficient food to the area, periods of high turbidity or temperature anomalies. There are regions in the northern Gulf of Mexico where dead standing colonies occur (Brooke \& Schroeder 2007), so coral colonies have formed in the past and subsequently 
died, but the 'no coral' areas in the present study appear not to have supported corals in the past. Different areas in the northern Gulf of Mexico support distinctly different morphotypes of $L$. pertusa; one of these is heavily calcified and has been termed Brachycephala, and the other, the Gracilis form, has a more fragile skeleton (Cairns 1979). The causes of these differences in skeletal structure are unknown, and until the present study nothing was known about growth of either morphotype of $L$. pertusa in the Gulf of Mexico, nor have the reasons for uncolonized areas been studied experimentally. The present study used only the heavily calcified morphotype that occurs at the Viosca knoll site, and was designed to accomplish 2 specific objectives: (1) to determine whether uncolonized exposed carbonate areas could support coral growth and survival and (2) to directly measure growth rates of $L$. pertusa within an area of the northern Gulf of Mexico dominated by large coral thickets.

\section{MATERIALS AND METHODS}

Study site. The study site was located on a feature called Viosca Knoll in the northern Gulf of Mexico, which lies in the corner of adjacent Minerals Management Service lease blocks located between $29^{\circ} 09.09^{\prime} \mathrm{N}, 88^{\circ} 01.58^{\prime} \mathrm{W}$ (lease block 869) and $29^{\circ} 09.63^{\prime} \mathrm{N}, 88^{\circ} 01.06^{\prime} \mathrm{W}$ (lease block 826). This area represents the most well-documented and, as far as we know, the most extensive Lophelia pertusa reef in the Gulf of Mexico. Viosca Knoll is a mound rising to $90 \mathrm{~m}$ above the surrounding seafloor to a minimum depth of approximately $430 \mathrm{~m}$ in the southwest corner of lease block 826. Bottom temperatures during the study period ranged from 7 to $9.6^{\circ} \mathrm{C}$ (CSA International 2007). Bottom sediments consisted of silty clay, authigenic carbonate and shell hash. There are extensive authigenic carbonate formations on the crest and flanks of the mound, which have been successfully colonized by $L$. pertusa and other benthic fauna (Moore \& Bullis 1960, Schroeder 2002). More recent studies have characterized the coral and chemosynthetic communities in this area (Sulak et al. 2007, Cordes et al. 2008). Coral colonies have the bushy colony form typical of $L$. pertusa, composed of irregular, dendritic branches that are highly anastomosed (Cairns 1979). Individual colonies range in size from a few centimeters to over $1.5 \mathrm{~m}$ in diameter, and aggregations of closely associated colonies create linear formations up to 1.5 to $2 \mathrm{~m}$ in height. Many of the aggregated colonies appear to form thickets of dead coral skeleton, supporting the live outer branches. Other regions of the knoll have large areas of exposed carbonate that has not been colonized by sessile fauna.
Sampling. Samples of Lophelia pertusa were collected from large live coral colonies at Viosca Knoll $\left(29^{\circ} 09.63^{\prime} \mathrm{N}, 88^{\circ} 01.06^{\prime} \mathrm{W}\right)$ in July 2004 , using the Johnson Sea-Link submersible operated by Harbor Branch Oceanographic Institution. The samples were placed in a large acrylic box on the front of the submersible. The thick walls of the box maintained approximately ambient bottom temperatures $\left(\sim 8^{\circ} \mathrm{C}\right)$ during transport to the surface. On the surface, the fragments were transferred to the shipboard cold room and maintained at $8^{\circ} \mathrm{C}$ in large, aerated tanks. Fragments of coral with 10 to 20 intact polyps were transferred to plastic tubs containing Alizarin red $\left(10 \mathrm{mg} \mathrm{l}^{-1}\right)$ and held for $48 \mathrm{~h}$. This technique was originally used for staining shallow-water corals (Lamberts 1974, Dustan 1975), but $L$. pertusa incorporates the stain more slowly than shallow species $(<24 \mathrm{~h})$ and therefore required a longer staining period. In addition to the stain, a colored cable tie was placed at the base of the terminal polyp on each fragment as a marker for branch extension and addition of new polyps. The fragments were photographed after the cable tie was attached and Image Tool (University of Texas Health Science Center at San Antonio [UTHSCSA]) was used to measure the distance from the cable tie to the rim of the calyx at 3 different points around the polyp, to create pre-deployment baseline data for growth measurements. The base of each fragment was placed in quicksetting cement in a $3 / 4$ inch PVC union fitting, and held steady for approximately 2 min in air until the cement was set. Exposure to air did not have any apparent negative effect on the corals, which displayed expanded polyps shortly after the fragments (in their fittings) were transferred to clean seawater. The fragments were held at $8^{\circ} \mathrm{C}$ until deployment the following day (24 July). The number of live, dead and broken polyps was recorded for every fragment before it was attached to the transplant unit (Fig. 1). Each of these units was comprised of a concrete base $(25 \mathrm{~cm}$ diameter) embedded with 4 PVC fittings that enabled the coral fragments to be easily and securely attached to the unit without damage. Immediately before deployment, the acrylic box on the front of the submersible was filled with cold $\left(8^{\circ} \mathrm{C}\right)$ seawater, and the transplant units were placed inside. There were 8 transplant units, each with 4 replicate fragments attached for a total of 32 coral fragments deployed. Four units were placed within coral thickets at Viosca Knoll (460 m), which was obviously appropriate habitat for coral growth, and also served as a control for any mortality associated with manipulation. That is, we know that coral can survive and grow well in this area, so if we observed high transplant mortality, it would probably have been due to some handling artifact. The remaining 4 units were deployed in an area with no coral at 


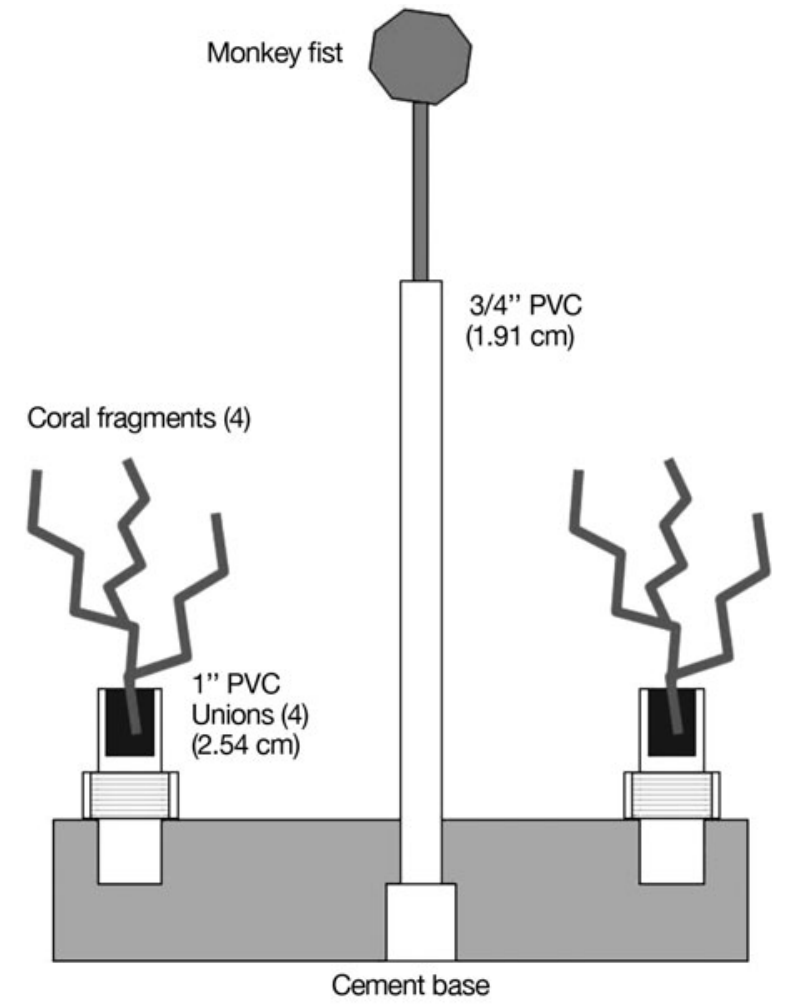

Fig. 1. Diagram of a single transplant unit showing a cross section of the arrangement of coral fragments on the cement base $(25 \mathrm{~cm}$ diameter)

$507 \mathrm{~m}$ depth, $\sim 0.25 \mathrm{~km}$ to the southeast of the high coral area, to determine whether this habitat could support coral survival and growth.

The transplants were recovered in September 2005 after $414 \mathrm{~d}$ (approximately $13.5 \mathrm{mo}$ ) in situ, using the Johnson Sea-Link submersible. All 4 units were recovered from the area with no coral, but only 3 of those in the high coral were found. The units were placed in the acrylic box and transported to the surface at ambient seafloor temperature. The units were taken immediately to the cold room aboard ship, and the fragments were removed from the concrete bases and placed in plastic containers of cold $\left(8^{\circ} \mathrm{C}\right)$ seawater. Each fragment was photographed after recovery in the same position as the predeployment images, to visually document pre- and post-deployment condition, and the number of live, dead and broken polyps was recounted to compare with the predeployment data. The percent survival and number of new polyps were assessed for each fragment. Growth was measured for those (terminal) polyps tagged with cable ties as distance from cable tie to tip of calyx at 3 different points for comparison with pre-deployment measurements, and for all other polyps new growth (i.e. unstained skeleton) was mea- sured using calipers. Total linear growth (total linear extension across all polyps) and average growth (total linear extension/number of polyps) were calculated for each fragment. Since the 4 fragments on each transplant unit were not true replicates, these were pooled to create a 'unit' mean value. To avoid confusion in terminology, 'average' will only apply to the growth measurements as described above, in all other cases 'mean' will be used to describe an arithmetic mean. All average and mean values are presented \pm SD. The unit means were then used for comparison of high coral $(\mathrm{n}=3)$ and no coral $(\mathrm{n}=4)$ percent survival, number of new polyps, total linear growth and average growth using 1-way ANOVA. Tests for normality and homogeneity of variance (Levene's test) were performed prior to the ANOVA, and data transformation was performed if needed.

Pieces of the skeleton showing evidence of growth were embedded in plastic casting resin under vacuum to remove air bubbles from the complex skeletal structure, cut into thin slices with a circular diamond blade and polished manually with a series of buffing papers to enable visualization of the stained growth bands. Images were taken under a Zeiss dissection microscope using an Optronics Microfire digital camera system. These images were imported into Image Tool and the distances from the stain bands to the outer edges of the calices were measured. In combination, these techniques provided measurements of linear and lateral extension.

\section{RESULTS}

The fragments from both the high coral and no coral areas showed a high level of survival (Table 1), and new growth was clearly visible on the fragments from both sites, particularly on the heavily stained fragments. Growth was focused primarily at the terminal ends of the branches (Fig. 2), but additional growth was also observed on the tips of the older polyps. Percentage survival of transplants deployed in high coral $(91.2 \pm 8.74 \%)$ and no coral areas $(91.15 \pm 3.78 \%)$ (Fig. 3) were not significantly different $\left(F_{1,5}=0.002\right.$, $\mathrm{p}=0.97$ ). The mean total linear extension for the high

Table 1. Lophelia pertusa. Summary of growth statistics from the transplants deployed in both high coral $(\mathrm{n}=3)$ and no coral $(\mathrm{n}=4)$ areas for $414 \mathrm{~d}(\sim 13.5 \mathrm{mo})$. Values are given $\pm \mathrm{SD}$

\begin{tabular}{|lcccc|}
\hline & Polyp survival & \multicolumn{2}{c|}{ Growth $(\mathrm{mm})$} & New \\
\cline { 3 - 4 } & $(\%)$ & Total & Average & polyps (n) \\
\hline High coral & $91.20 \pm 8.74$ & $19.55 \pm 8.04$ & $4.27 \pm 0.88$ & $3.31 \pm 1.25$ \\
No coral & $91.15 \pm 3.78$ & $10.85 \pm 8.05$ & $2.76 \pm 2.15$ & $3.52 \pm 1.65$ \\
\hline
\end{tabular}



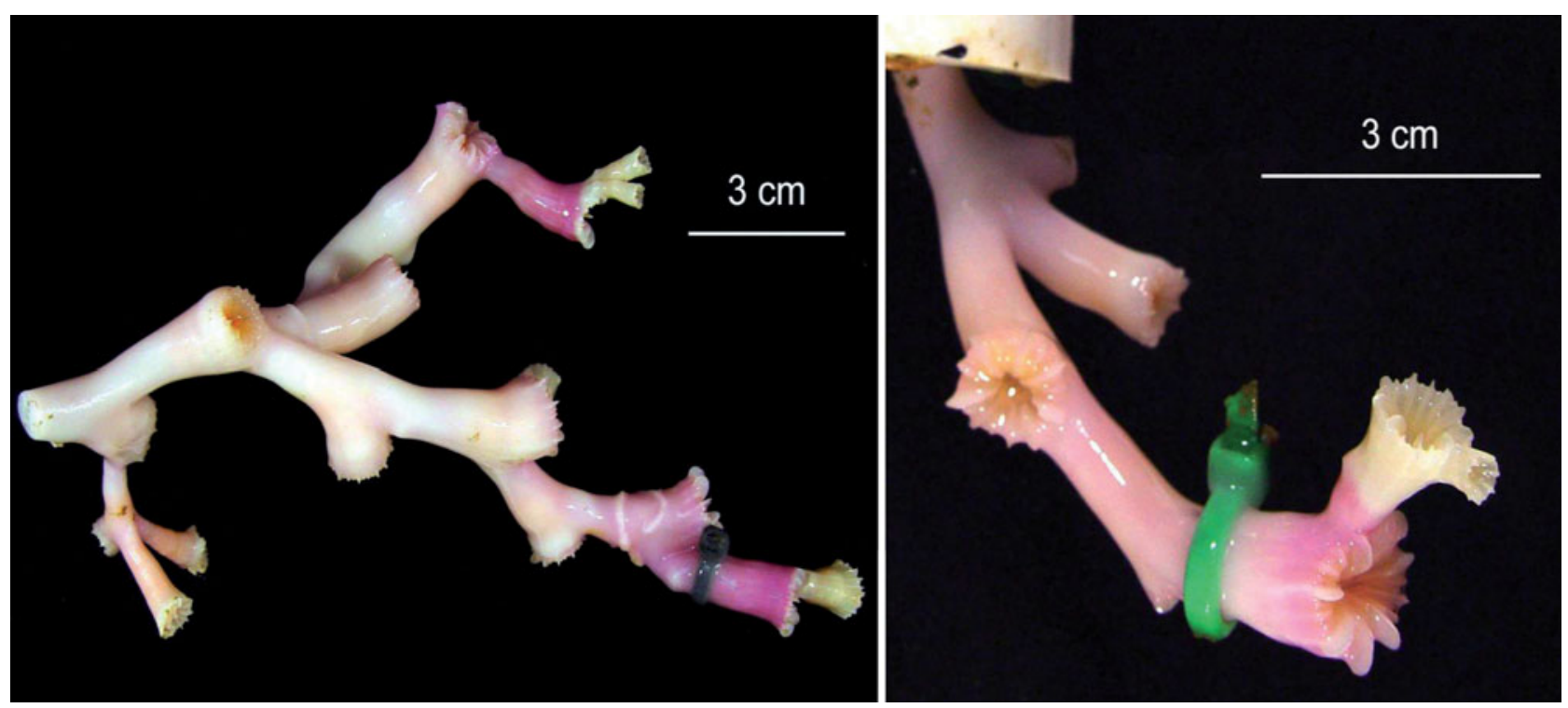

Fig. 2. Lophelia pertusa. Post-recovery fragments from 2 different transplant blocks showing new growth, as unstained white skeleton, at the terminal polyps. Darker staining also indicates that areas of active growth are focused at the ends of the branches. Transplant block was indicated using different colored cable ties

coral and no coral sites was $19.55 \pm 8.04$ and $10.85 \pm$ $8.05 \mathrm{~mm}$, respectively, for the total deployment period. The average growth was calculated similarly for high coral versus no coral areas and was $4.27 \pm 0.88$ and $2.76 \pm 2.15 \mathrm{~mm}$, respectively (Fig. 4). These values were for the $414 \mathrm{~d}$ of the transplant deployment period, which translates into annual total growth of 17.24 and

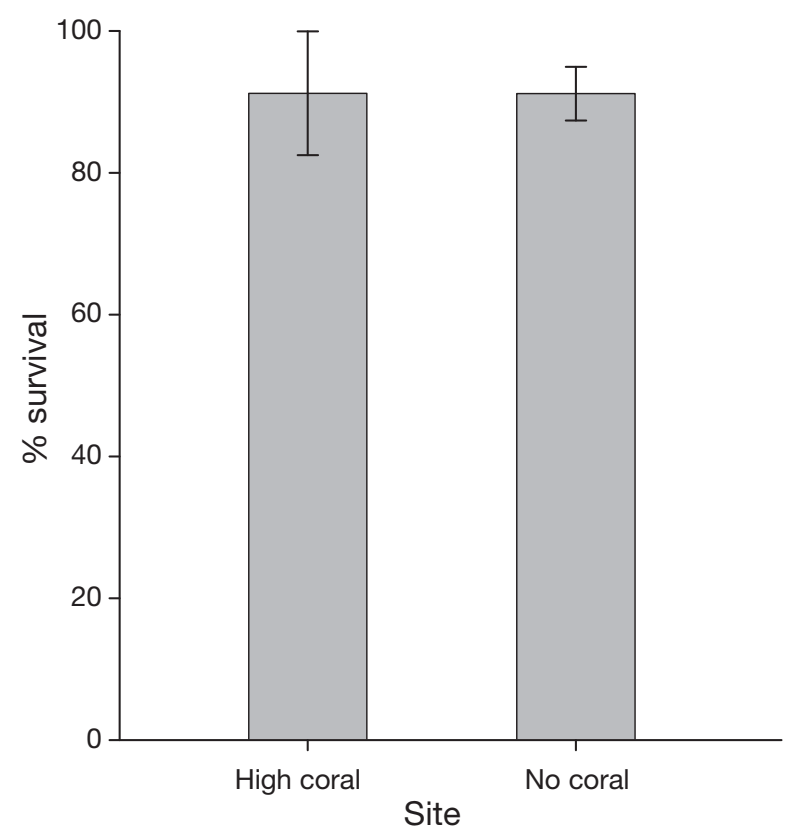

Fig. 3. Lophelia pertusa. Mean survival of transplants in high coral $(n=3)$ and no coral $(n=4)$ sites. Error bars represent SD
$9.57 \mathrm{~mm}$, and average growth of 3.77 and $2.44 \mathrm{~mm}$ for high coral and no coral areas, respectively. ANOVA revealed no significant difference in either total $\left(F_{1,5}=\right.$ $2.00, \mathrm{p}=0.21)$ or average $\left(F_{1,5}=0.71, \mathrm{p}=0.44\right)$ linear growth between transplant habitats. The average number of new polyps per fragment in the high coral area $(3.08 \pm 1.46)$ was similar to that in the no coral

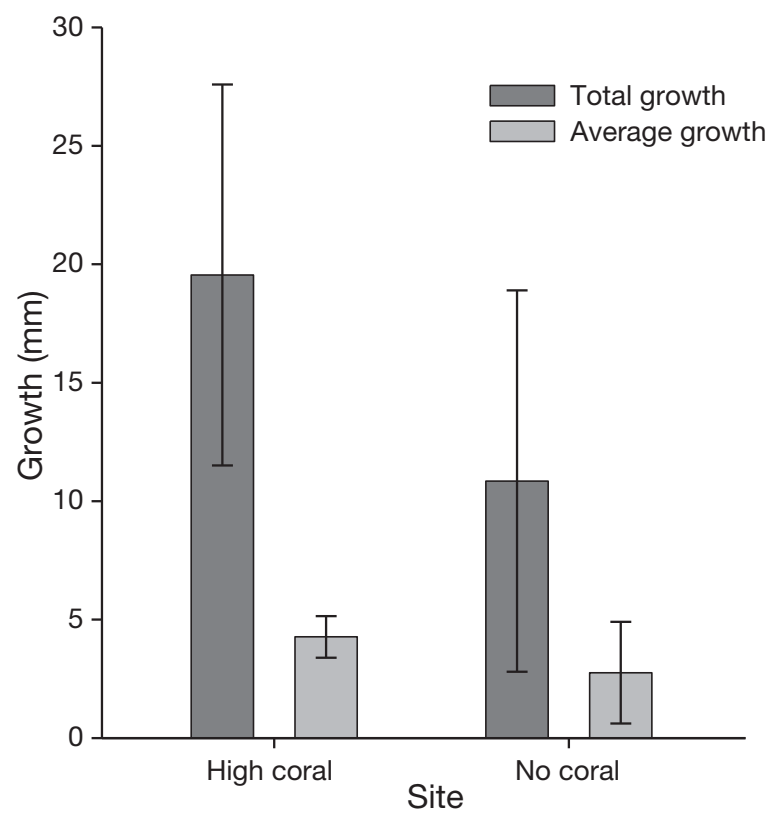

Fig. 4. Lophelia pertusa. Total and average linear growth observed in transplants deployed in high coral $(\mathrm{n}=3)$ and no coral $(\mathrm{n}=4)$ sites between July 2004 and September 2005. Error bars represent SD 


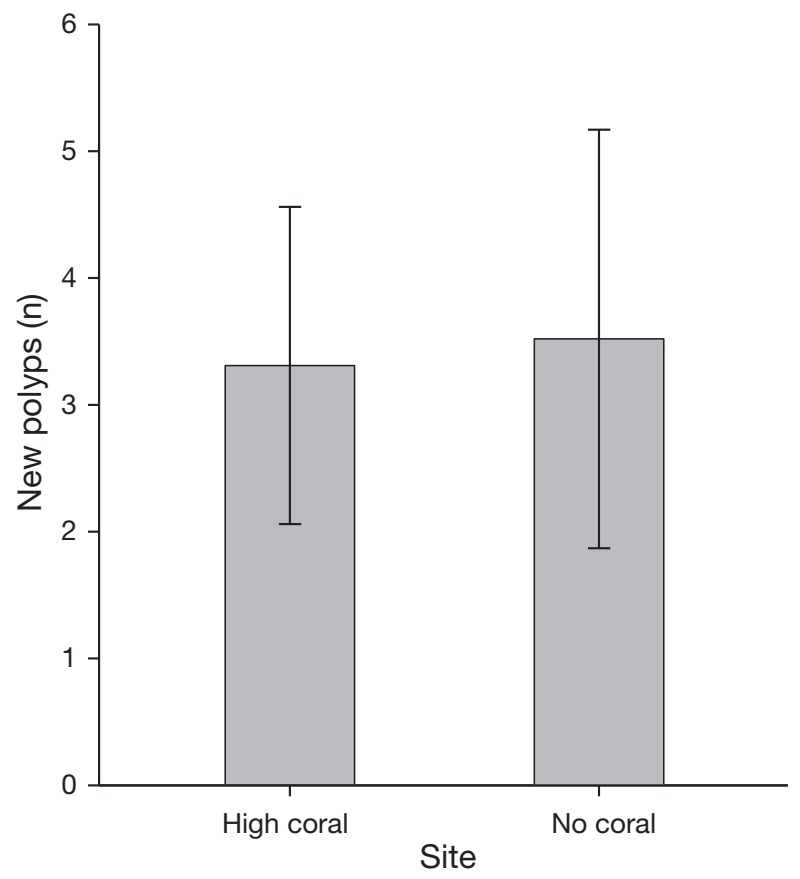

Fig. 5. Lophelia pertusa. Mean number of new polyps found in transplants in high coral $(\mathrm{n}=3)$ and no coral $(\mathrm{n}=4)$ sites. Error bars represent SD

area (3.52 \pm 1.65) (Fig. 5), and there was no significant difference $\left(F_{1,5}=0.03, \mathrm{p}=0.86\right)$ between the areas. The results of the ANOVAs for all of these survival and growth variables are summarized in Table 2.

The stained growth bands from the thin resin sections were clearly visible in the younger, more heavily stained polyps, and it is apparent that there were 2 growth centers: one on the outer edge of the calyx and
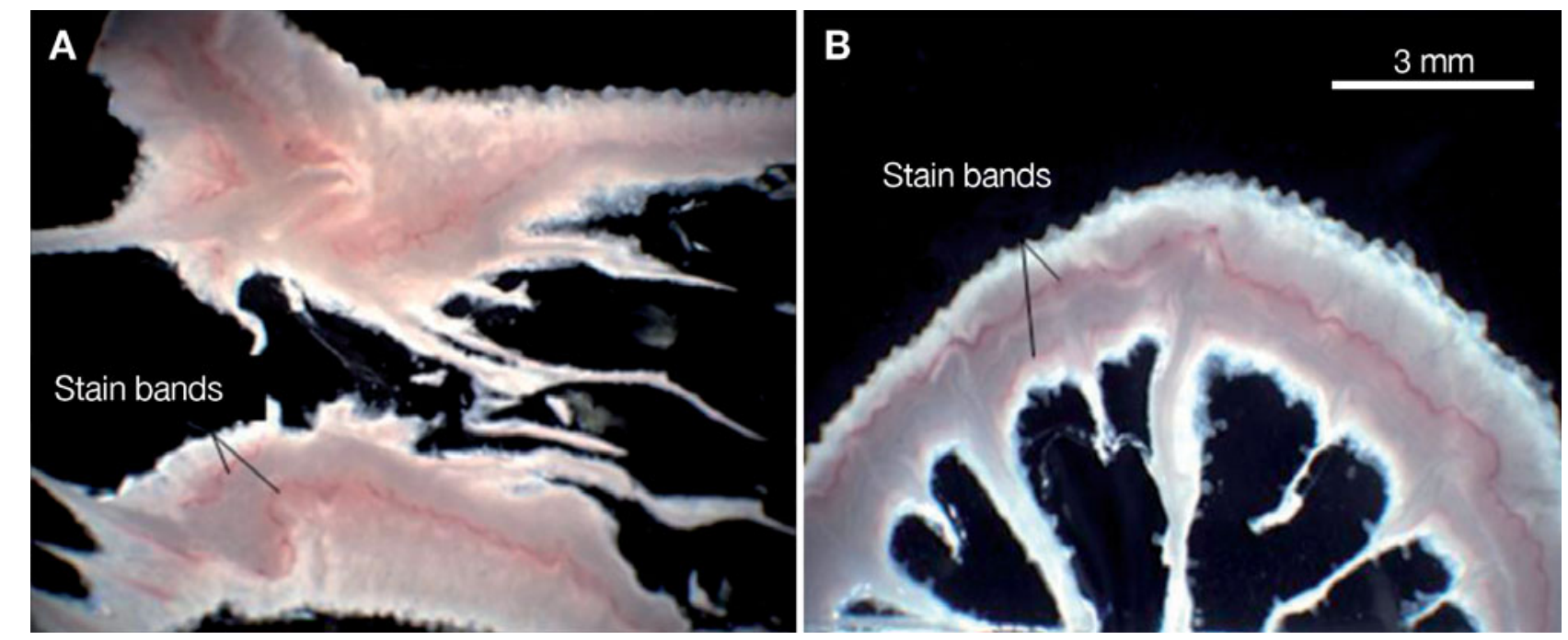

Fig. 6. Lophelia pertusa. (A) Lengthwise and (B) transverse sections of stained transplant fragments showing 2 growth centers

(stain bands) for each section. Scale bar in (B) is representative of both images another on the inner edge near the septae (Fig. 6). The average ( $\mathrm{n}=5$ polyps) outer growth increment was $278.3 \pm 20.33 \mu \mathrm{m}$, and the inner growth was $99.89 \pm$ $7.13 \mu \mathrm{m}$. This translates into annual lateral increments of 245.36 and $88.07 \mu \mathrm{m}$, respectively; however, the deposition of the skeleton around the calyx was not consistent (that is, more calcification occurred in some parts of the calyx than others, as is apparent in Fig. 6B), so the quantity of calcification cannot be extrapolated to with confidence.

\section{DISCUSSION}

The growth potential of Lophelia pertusa and other structure-forming coral species is a critical component of not only initial reef development, but also the resilience of these systems to physical damage and less direct threats such as changes in ocean chemistry. As previously mentioned, there have been multiple attempts to measure L. pertusa growth, and the resulting estimates have varied greatly. In the present study, the growth observed in experimental fragments was also extremely variable, as was the degree to which each fragment incorporated the Alizarin stain. This is a 'vital' stain which was incorporated into the actively growing parts of the skeleton, so the more heavily stained parts of the branches, invariably near the tips, were presumably the areas of most active growth. The polyps that were marked with cable ties were missing from some of the recovered fragments, but it is unclear whether this was caused by the presence of the cable ties or whether terminal polyps are frequently broken off under normal circumstances. The young terminal polyps are much more 
Table 2. ANOVA results for total growth, average growth, percent surplaced in high coral $(n=3)$ and no coral $(n=4)$ areas. There was no significant difference between sites for any of the variables $(p>0.05)$

\begin{tabular}{|llcccc|}
\hline Variable & \multicolumn{1}{c}{ Source } & df & MS & $F$ & p \\
\hline Survival & Site (High vs. No coral) & 1 & 0.01 & 0.00 & 0.99 \\
& Transplant unit & 5 & 39.09 & & \\
Total growth & Site (High vs. No coral) & 1 & 129.78 & 2.00 & 0.22 \\
& Transplant unit & 5 & 64.79 & & \\
Average growth & Site (High vs. No coral) & 1 & 2.14 & 0.71 & 0.44 \\
& Transplant unit & 5 & 3.04 & & \\
New polyps & Site (High vs. No coral) & 1 & 0.08 & 0.03 & 0.86 \\
& Transplant unit & 5 & 2.27 & & \\
\hline
\end{tabular}
vival and number of new polyps for Lophelia pertusa transplants

none of them extended beyond the length of a single adult polyp. In other words, the maximum extension that was obtained in 1 yr was approximately 1 polyp length. This is a useful observation, especially if it holds true for other locations, as it defines the upper limit for colony growth rate. The average growth observed in the present study represented a combination of minor growth of existing polyps and addition of new polyps. The differences in linear extensions observed between mature polyps $(\leq 5 \mathrm{~mm}$ $\left.\mathrm{yr}^{-1}\right)$ and new polyps $\left(\leq 16 \mathrm{~mm} \mathrm{yr}^{-1}\right)$ may help explain the discrepancies between the documented growth rates for this species.

The stain bands on the coral sections illusfragile than the older polyps, and are extended the furthest, so it is possible that they are often damaged.

The average linear extension rates measured in the present study fell slightly below the published range of 6 to $35 \mathrm{~mm} \mathrm{yr}^{-1}$ for this species (Wilson 1979b, Mikkelsen et al. 1982, Freiwald et al. 1997, Mortensen \& Rapp 1998, Mortensen 2000, Gass \& Roberts 2006, Orejas et al. 2008). A slower than average growth rate was unexpected since the coral colonies at this site appear to be robust and healthy with large polyps ( $\sim \mathrm{cm}$ diameter) and up to $15 \%$ of live coral cover (CSA International 2007). In addition, the depth and temperature $\left(<500 \mathrm{~m}\right.$ and 7 to $\left.9.6^{\circ} \mathrm{C}\right)$ were not too deep and/or cold for this species, which could have caused a slower growth rate than for other locations. As mentioned in the introduction, some of the variation in the documented growth values is a result of the methodological approach and the interpretation of growth. For example, Orejas et al. (2008) measured the total linear growth on their coral fragments. This is valid for those particular fragments, but this approach makes it hard to compare with other studies since the total linear growth will depend on the initial size of the fragment and the number of growing tips (their aquaria were also maintained at $\sim 11.5^{\circ} \mathrm{C}$, which is warmer than other studies). Linear growth from the published studies falls into 2 groupings: $\sim 5$ to $7 \mathrm{~mm} \mathrm{yr}^{-1}$ (Duncan 1877, Wilson 1979b, Mortensen \& Rapp 1998, present study) or $\sim 20$ to $35 \mathrm{~mm} \mathrm{yr}^{-1}$ (Mikkelsen et al. 1982, Freiwald et al. 1997, Bell \& Smith 1999, Gass \& Roberts 2006, Orejas et al. 2008). If we examine the growth pattern of Lophelia pertusa fragments in the present study, it is apparent that new polyps can bud from any of the polyps along the length of a branch, but for the most part it was those near the branch tips that created new polyps. The greatest growth extension observed during this experiment for a single polyp was $16.3 \mathrm{~mm}$, which is slightly less than the average length of the mature polyps $(\sim 20 \mathrm{~mm})$. Although several polyps along a single branch budded multiple new polyps, trated the double growth center, which introduces an additional level of complexity when assessing growth through lateral banding patterns; 6 visible bands may be interpreted as $6 \mathrm{yr}$ of growth, when they actually represent only 3 yr of growth. This has quite a significant effect on age calculations, if the growth bands are annual, and an even greater effect if they occur more frequently. These growth bands were observed most strongly on the younger polyps, but whether these double growth centers continue in mature polyps is not known. The alizarin was not taken up well by mature polyps, which may simply require a longer staining period, but aquarium studies (S. Brooke unpubl. data) on stained fragments showed no additional growth of older polyps over nearly 1 yr. It is possible that when conditions are suboptimal, the corals just maintain skeletal structure without additional growth, or when polyps reach a certain size, growth may slow or cease. If this species is capable of simply putting their growth on hold under certain circumstances, this may allow them to withstand unfavorable conditions, at least temporarily. It also is apparent from the stain bands that lateral skeletal deposition is not equal over the entire circumference of the polyp (refer to Fig. 6), but the causes of this inconsistency are unknown, and may simply be attributed to biological variability; however, this is a potential complication in the interpretation of radial growth rates.

In addition to investigating growth rates and patterns, the present study was designed to test whether Lophelia pertusa distribution at Viosca Knoll may be driven by habitat suitability. The results show that transplant survival was high in both dense coral and no coral locations, and growth and number of new polyps showed no significant difference between sites, which indicates that some factor that influences recruitment and juvenile success (e.g. larval supply, post-settlement mortality) is likely responsible for the absence of corals on apparently suitable bare substrata. This is supported by the observation that there were no indi- 
cations of previous coral colonies which settled and subsequently died. The population genetics of $L$. pertusa are being studied in the Gulf of Mexico and western Atlantic (C. Morrision et al. unpubl. data), but the small-scale recruitment patterns, dispersal abilities and settlement cues of $L$. pertusa larvae are still unknown. The complex manipulative approach of the present study cannot be applied to a wide range of ecosystems because of the logistics and expense; however, the staining techniques could be applied to other in situ equipment such as deep-sea landers, for longterm deployment, incorporated into controlled laboratory experiments or used to model growth of other calcified species.

Acknowledgements. This work was funded by the Minerals Management Service contract no. 1435-01-03-CT-72323 to Continental Shelf Associates. Thanks go to the crew of the RV 'Seward Johnson' and the Johnson Sea-Link submersible, Harbor Branch Oceanographic Institution and the students of the Oregon Institute of Marine Biology for their assistance with fieldwork and data collection.

\section{LITERATURE CITED}

Adkins JF, Henderson GM, Wang SL, O'Shea S, Mokadem F (2004) Growth rates of deep sea scleractinia Desmophyllum cristigalli and Enallopsammia rostrata. Earth Planet Sci Lett 227:481-490

Aharon P, Fu B (2000) Microbial sulfate reduction rates and oxygen isotope fractionations at oil and gas seeps in deepwater Gulf of Mexico. Geochim Cosmochim Acta 64: 233-246

Andrews AH, Cailliet GM, Kerr LA (2005) Investigations of age and growth for three deep-sea corals from the Davidson Seamount off central California. In: Freiwald A, Roberts JM (eds) Cold-water corals and ecosystems. Springer, Berlin, p 1021-1038

Bell N, Smith J (1999) Coral growing on North Sea oil rigs. Nature 402:601

Boetius A, Ravenschlag K, Schubert CJ, Rickert D and others (2000) A marine microbial consortium apparently mediating anaerobic oxidation of methane. Nature 407:623-626

Brooke S, Schroeder WW (2007) State of deep coral ecosystems in the Gulf of Mexico region: Texas to the Florida Straits. In: Lumsden SE, Hourigan TF, Bruckner AW (eds) The state of deep coral ecosystems of the United States. NOAA Tech Memo NOS-CRCP-3, Silver Spring, MD

Cairns S (1979) The deep-water Scleractinia of the Caribbean Sea and adjacent waters. Stud Fauna Curaçao 57:1-341

Cairns SD (1994) Scleractinia of the temperate North Pacific. Smithsonian Contributions to Zoology 557, Smithsonian Institution Press, Washington, DC

> Cairns SD, Parker SA (1992) Phylogenetic implications of calcium carbonate mineralogy in the Stylasteridae (Cnidaria; Hydrozoa). Palaios 7:96-107

> Cheng H, Adkins J, Edwards RL, Boyle EA (2000) U-Th dating of deep sea corals. Geochim Cosmochim Acta 64: 2401-2416

> Cordes E, McGinley MP, Podowski EL, Becker E, LessardPilon S, Viada SD, Fisher CR (2008) Coral communities of the deep Gulf of Mexico. Deep-Sea Res I 55:777-787
CSA International (2007) Characterization of northern Gulf of Mexico deepwater hard bottom communities with emphasis on Lophelia coral. OCS Study MMS 2007-044. US Department of the Interior, Minerals Management Service, Gulf of Mexico OCS Region, New Orleans, LA

Duncan PM (1877) On the rapidity of growth and variability of some Madreporaria on an Atlantic cable with remarks on the rate of accumulation of foraminiferal deposits. Proc R Soc Lond 26:133-137

Dustan P (1975) Growth and form in the reef-building coral Montastrea annularis. Mar Biol 33:101-107

Frederiksen RA, Jensen A, Westerberg H (1992) The distribution of the scleractinian coral Lophelia pertusa around the Faroe Islands and the relation to internal mixing. Sarsia $77: 157-171$

Freiwald A, Henrich R, Pätzold J (1997) Anatomy of a deepwater coral reef mound from Stjernsund, West-Finnmark, Northern Norway. In: James NP, Clarke JAD (eds) Coolwater carbonates. Spec Publ 56, SEPM, Tulsa, OK, p 141-162

Freiwald A, Fosså JH, Grehan A, Koslow T, Roberts JM (2004) Cold-water coral reefs. UNEP-WCMC, Cambridge

> Gass SE, Roberts JM (2006) The occurrence of the cold water coral Lophelia pertusa (Scleractinia) on oil and gas platforms in the North sea: colony growth, recruitment and environmental controls on distribution. Mar Pollut Bull 52: $549-559$

Grigg RW (1976) Fishery management of precious and stony corals in Hawaii. Sea Grant Technical Report, University of Hawaii, Honolulu, HI

Grigg RW (2002) Precious corals in Hawaii: discovery of a new bed and revised management measures for the existing beds. Mar Fish Rev 64:13-20

Guinotte JM, Orr J, Cairns SD (2006) Will human-induced changes in seawater chemistry alter the distribution of deep-sea scleractinian corals? Front Ecol Environ 4: 141-146

Hovland MR, Farestveit R, Mortensen PB (1994) Large cold water coral reefs off mid Norway: A problem for pipelaying? Proc Oceanol Int, 8-11 Mar 1994, Brighton, p 35-40

Hovland MR, Mortensen PB, Thomsen E, Brattegard T (1997) Substratum-related ahermatypic corals on the Norwegian continental shelf. Proc 8th Int Coral Reef Symp 2: 1203-1206

Lamberts AE (1974) Measurement of Alizarin deposited by coral. Proc 2nd Int Coral Reefs Symp 2:241-244

Love MS, Yoklavich MM, Black BA, Andrews AH (2007) Age of black coral (Antipathes dendrochristos) colonies with notes on associated invertebrate species. Bull Mar Sci 80: 391-399

Lumsden SE, Hourigan TF, Bruckner AW (2007) The state of deep coral ecosystems of the United States. NOAA Tech Memo NOS-CRCP-3, Silver Spring, MD

Mikkelsen N, Erlenkauser H, Killingley JS, Berger WH (1982) Norwegian corals: radiocarbon and stable isotopes in Lophelia pertusa. Boreas 5:163-171

Moore DR, Bullis HR (1960) A deep-water coral reef in the Gulf of Mexico. Bull Mar Sci 10:125-128

Mortensen PB (2000) Lophelia pertusa (Scleractinia) in Norwegian waters. Distribution, growth, and associated fauna. PhD thesis, University of Bergen

Mortensen PB (2001) Aquarium observations on the deepwater coral Lophelia pertusa (L., 1758) (Scleractinia) and selected associated invertebrates. Ophelia 54:83-104

Mortensen PB, Buhl-Mortensen L (2005) Morphology and growth of the deep-water gorgonians Primnoa resedaeformis and Paragorgia arborea. Mar Biol 147:775-788 
Mortensen PB, Rapp HT (1998) Oxygen and carbon isotope ratios related to growth line patterns in skeletons of Lophelia pertusa (L) (Anthozoa: Scleractinia): implications for determination of linear extension rates. Sarsia 83: 433-446

Mortensen PB, Hovland M, Brattegard T, Farestveit R (1995) Deep water bioherms of the scleractinian coral Lophelia pertusa (L.) at $64^{\circ} \mathrm{N}$ on the Norwegian shelf: structure and associated megafauna. Sarsia 80:145-158

Noé SU, Lembke-Jene L, Dullo WC (2008) Varying growth rates in bamboo corals: sclerochronology and radiocarbon dating of a mid-Holocene deep-water gorgonian skeleton (Keratoisis sp.: Octocorallia) from Chatham Rise (New Zealand). Facies 54:151-166

Orejas C, Gori A, Gili JM (2008) Growth rates of live Lophelia pertusa and Madrepora oculata from the Mediterranean Sea maintained in aquaria. Coral Reefs 27:255

Paull CK, Neumann AC, am Ende BA, Ussler W III, Rodriguez NM (2000) Lithoherms on the Florida-Hatteras shelf. Mar Geol 166:83-101

Risk MJ, Heikoop JM, Snow MG, Beukens R (2002) Lifespan and growth patterns of two deep sea corals: Primnoa resedaeformis and Desmophyllum cristigalli. Hydrobiologia 471:125-131 Radiocarbon-based ages and growth rates of Hawaiian deep-sea corals. Mar Ecol Prog Ser 327:1-14

Roberts JM, Anderson RM (2002) A new laboratory method of monitoring deep-sea coral polyp behaviour. Hydrobiologia 471:143-148

Roberts JM, Wheeler AJ, Freiwald A, Cairns SD (2009) Coldwater corals: the biology and geology of deep-sea coral habitats. Cambridge University Press, Cambridge

Rogers AD (1999) The biology of Lophelia pertusa (Linnaeus 1758) and other deep-water reef-forming corals and impacts from human activities. Int Rev Hydrobiol 844: 315-406

Submitted: March 2, 2009; Accepted: September 29, 2009
Ross SW, Nizinski MS (2007) State of deep coral ecosystems in the US southeast region: Cape Hatteras to southeastern Florida. In: Lumsden SE, Hourigan TF, Bruckner AW (eds) The state of deep coral ecosystems of the United States. NOAA Tech Memo NOS-CRCP-3, Silver Spring, MD

Schroeder WW (2002) Observations of Lophelia pertusa and the surficial geology at a deep-water site in the northeastern Gulf of Mexico. Hydrobiologia 471:29-33

Squires DF (1964) Fossil coral thickets in Wairapa, New Zealand. J Paleontol 38:904-915

Stromgren T (1971) Vertical and horizontal distribution of Lophelia pertusa (Linne) in Trondheimsfjorden on the west coast of Norway. K Norske Vidensk Skr 6:1-9

Sulak KJ, Brooks R, Luke KE, Norem AD and others (2007) Demersal fishes associated with Lophelia pertusa coral and hard-substrate biotopes on the continental slope, northern Gulf of Mexico. Bull Mar Sci 81:65-92

Thiem O, Ravagnan E, Fossa JH, Bernsten J (2006) Food supply mechanisms for cold water corals along a continental shelf. J Mar Syst 60:207-219

Thresher RE, MacRae CM, Wilson CM, Gurney R (2007) Environmental effects on the skeletal composition of deepwater gorgonians (Keratoisis spp: Isididae). Bull Mar Sci 81:409-422

White M, Bashmachnikov I, Aristegui J, Martins A (2007) Physical processes and seamount productivity. In: Pitcher TJ, Morato T, Hart PJB (eds) Seamounts: ecology, fisheries and conservation. Blackwell Publishing, Oxford, p 65-84

Wilson JB (1979a) The distribution of the coral Lophelia pertusa (L.) in the north-east Atlantic. J Mar Biol Assoc UK 59:149-164

Wilson JB (1979b) Patch development of the deep-water coral Lophelia pertusa (L.) on Rockall Bank. J Mar Biol Assoc UK 59:165-177

Zibrowius H (1980) Les scléractiniaires de la Méditerranée et de l'Atlantique nord-oriental. Mem Inst Oceanogr 11: $1-226$

Proofs received from author(s): December 4, 2009 